Lucia Santaella é pesquisadora 1 A do CNPq, professora titular na pós-graduação em Comunicação e Semiótica e na pós-graduação em Tecnologias da Inteligência e Design Digital (PUCSP). Doutora em Teoria Literária pela PUCSP e Livre-docente em Ciências da Comunicação pela USP. Foi professora convidada em várias universidades do exterior. Já levou à defesa 240 mestres e doutores. Publicou 42 livros e organizou 16, além da publicação de perto de 400 artigos no Brasil e no exterior. Recebeu os prêmios Jabuti (2002, 2009, 2011, 2014), o prêmio Sergio Motta (2005) e o prêmio Luiz Beltrão (2010).

\title{
A ONIPRESENÇA DO DESIGN
}

Lucia Santaella 
Este artigo discute os desdobramentos do conceito e das práticas do design a partir de seu núcleo semântico que se encontra na noção de projeto.

Assim considerado, os inumeráveis níveis e facetas de materialização e operacionalidade do design derivariam da fonte primeira que reside na projeção mental do ato de conceber, uma projeção que é colocada à prova no teste de sua realização tendo em vista os matérias, meios e técnicas de que cada momento histórico dispõe. Tomando como base a pirâmide de Mensvoort dos degraus ascendentes que são percorridos por uma invenção tecnológica, são explorados os níveis de penetração e aceitação dos designs na vida social.

U Palavras-chave: design, projeto, pirâmide de $\widetilde{\Upsilon}$ Mensvoort, tecnologia.
This paper discusses the unfolding of the concept and practices of design from its semantic nucleus that is found in the notion of project. Thus considered, the innumerable levels and facets of design materialization and operability would derive from the first source that lies in the mental projection of the act of conceiving, a mental projection that is put into the test of its realization depending on the materials, means and techniques of each historical moment. Based on Mensvoort's pyramid of the ascending steps of a technological invention, the levels of penetration and acceptance of designs in social life are explored.

Keywords: design, project, Mensvoort's pyramid, technology. 
"To be human is to design" (Ser humano é projetar). Essa foi a frase de abertura do filósofo da tecnologia, Peter Paul Verbeek, na palestra que ministrou, no dia 04 de fevereiro, 2017, por ocasião do evento Transmediale-2017, Berlim. O Transmediale -- que celebrava seu $30^{\circ}$ aniversário, quando também se comemorava a reabertura da Haus der Culturen der Welt, depois de passar por um ano de reforma -- é, sem dúvida, a evento internacional sobre arte e mídia de maior importância no mundo. Além de palestras, mesas redondas, painéis de discussão, o evento também conta com uma exposição de arte no local e com uma parceria com o CTM que promove uma grande quantidade de exposições no campo da performance, vídeo, experimentações sonoras, música e arte digital que se espalha pela cidade durante algum tempo.

O que o Transmediale tem de fundamental é sua capacidade de agarrar no ar as questões veiculadas nas publicações e discussões mais recentes e candentes em mídia e arte no contexto do hemisfério norte e dar a elas uma composição coerentemente interconec- tada. O tema deste ano foi "Ever Elusive" ("Sempre Evasivo [Difícil]") com o qual se pretendeu discutir a condição acelerada do mundo atual e as dificuldades que apresenta para se saber onde o papel do humano termina e o da máquina começa. Com os sistemas de aprendizagem de máquinas, os agentes da inteligência artificial, as infraestruturas inteligentes e os organismos engenheirados desempenhando um papel cada vez mais importante, novas tecnoecologias e hibridações continuamente evoluem. Os atuais emaranhados, em que a tecnologia é sentida como natural e a mediação se torna imediata, influenciam o aguçamento das condições econômicas e sociopolíticas, colocando a primazia do agenciamento humano em questão.

Verbeek proferiu sua palestra em um painel que contava com uma apresentação coletiva na qual também estavam integrados dois outros teóricos e artistas do design Koert van Mensvoort e Floris Kaayk. O painel com o título de On the Origins of Androids tinha por intenção discutir seus provocativos projetos de cross mídia, todos eles direcionados para definições transformadoras das velhas dicotomias entre o natural e o artificial, de modo a apontar para visões de futuros potenciais nos quais a tecnologia e o corpo humano tenham se tornado inseparáveis.

Ao declarar que To be human is to design, Verbeek certamente está dando a design o seu sentido mais fundamental e amplo, ou seja, seu sentido de projeto, de modo que todas as formas históricas de manifestação do design, em especial as formas que se tornaram 
constantes a partir da produção industrial, ou seja, o design de produtos, o design gráfico, o design de moda e hoje o design digital, entre outros, são, na verdade, manifestações sensíveis de uma habilidade que está no cerne da constituição humana do ser humano, a saber, a habilidade de projetar. Não é por acaso que Verbeek buscou o fio condutor de sua apresentação no mito grego de Dedalus e Ícaro, mito da invenção como superação dos limites e competição com os deuses. Pelos fios dos tempos, a habilidade humana de projetar para transformar a natureza e seus ambientes, transformando, ao mesmo tempo, a si mesma, veio da pedra lascada até dar na profusão de gadgets com inteligência embarcada que hoje transbordam por nossa existência cotidiana.

Em um certo momento de sua apresentação integrada à de Verbeek, Mensvoort discorreu sobre a sua pirâmide muito genial acerca dos sete níveis ou etapas que vão do design, ou seja, do projeto, que ele chama genericamente de tecnologia, passando por sua realização material até a sua incorporação na vida individual e social. Esses níveis se caracterizam como previsão, operacionalização, aplicação, aceitação, vitalidade, invisibilidade e naturalização. Há possibilidade de movimentação para cima ou para baixo na sequência, mas os estágios inferiores devem ser preenchidos antes que se possa prosseguir para os demais. $\mathrm{O}$ autor indica que, para chegar a esses níveis, inspirou-se na hierarquia das necessidades de Maslow (1943). São elas: a) necessidades fisiológicas, ou seja, necessidades vitais que garantem a sobrevivência biológicas; $b$ ) necessidades de segurança, relativas à ordem, estabi- lidade e proteção; c) necessidades de filiação como amor, carinho e pertencimento; d) necessidades de reconhecimento como autoestima, realização pessoal e respeito dos outros; e) necessidades de autorrealização expressas no desenvolvimento interior (SOUZA, 2015). Muito utilizada no marketing organizacional, essa hierarquia tem recebido críticas baseadas em pesquisas empíricas. Entretanto, Mensvoort soube extrair dela inspiração que o levou a uma transposição que faz bastante sentido.

Existe um texto publicado, com cópia acessível nas redes em que Mensvoort (2014) detalha com minúcia e com fartura de exemplos os degraus de sua pirâmide. $\mathrm{O}$ eixo escolhido pelo autor para explicitar essa pirâmide é a tecnologia em si. Entretanto, se tomarmos o primeiro nível, o da previsão como sinônimo de projeto, os outros níveis vestem como uma luva todas as etapas implicadas no design quando concebido em seu sentido mais geral. Além disso, o que chamamos genericamente de tecnologia não faz sentido se não a concebermos como embutindo todas as fases do design que vão de seu projeto até a naturalização de suas produções na vida social. Portanto, tomando o texto de Mensvoort como base, assumirei a liberdade de retrabalhá-lo sob o ponto de vista do design, trazendo a discussão e os exemplos para os dispositivos tecnológicos atuais, pois são esses que estão mais perto de nós, integrados às nossas vidas. 


\section{PRO}

O termo empregado por Mensvoort é envision cuja tradução em português oscila entre visualizar, imaginar, conceber, prever, preconizar. Se quisermos condensar todos esses sentidos em uma só palavra creio que "projetar" caberia com uma certa justeza e, com ela, entraríamos no cerne da concepção de design.

Em artigo anterior, que teve por propósito estudar o conceito de design em Flusser (SANTAELLA, 2016), a partir do latim, desenvolvi uma análise etimológica do termo em suas traduções para o inglês, francês e português. De fato, os significados da palavra são escorregadios, além de, historicamente, terem adquirido novas feições. Infelizmente, a tradução para "desenho", em português, restringe demais a riqueza de seus possíveis sentidos. Não é por acaso que o termo adotado é "design", justamente para escapar das simplificações. Tendo em vista os objetivos do presente ensaio, selecionei o sentido de design que parece conter o maior potencial para se compreender todos os seus possíveis desdobramentos: esse é o sentido de projeto como propósito na sua rosácea de subsentidos, tais como: conceber, planejar, elaborar. Tudo indica que é nesse campo semântico que se insere o significado que Mensvoort quer dar a "envision", na base da pirâmide por ele elaborada.

Vale lembrar que a noção de design como habilidade de projetar está implícita no conceito de trabalho desenvolvido por Karl Marx. Embora essa noção seja bastante discutida pelos comentadores de Marx, devido a uma certa hesitação na própria obra marxista entre a concepção do trabalho concreto, criador e do trabalho abstrato, alienante, irei me deter aqui na ideia do trabalho concreto que, para Marx (cf. 2011) é trabalho projetado. O metabolismo entre ser humano e natureza é regulado pela mediação do trabalho.

Na época de Marx acreditava-se que, bem distinto do trabalho dos animais que apenas aplicam repetidamente os programas genéticos de que estão dotados, o trabalho humano pressupõe que esse trabalho seja projetado mentalmente. Recentemente, contudo, pesquisas sobre animais têm expandido sobremaneira os limites, anteriormente estabelecidos, de seus processos cognitivos. Shaviro (2015, p. 65) comenta um exemplo bastante significativo de um inseto, a mosca de frutas, cujo cérebro é minúsculo. Em vez de responder passivamente a um dado ambiente, esse inseto ativa e espontaneamente altera e controla seu ambiente, o que vem comprovar que cognição e inteligência não passam de uma questão de grau.

De todo modo, as pesquisas sobre animais não dei- 
xam de resguardar os graus de complexidade cognitiva que são específicos do humano. A ação humana implicada no trabalho em si é projetada no pensamento antes que o trabalho se realize ou enquanto ele se realiza. Portanto, projetar não inclui apenas os passos imprescindíveis à concretização das ações necessárias, mas também a capacidade de escolher os meios para isso. Do projeto com suas escolhas decorre que o trabalho humano tem uma margem de liberdade que permite ao ser humano transformar a natureza de acordo com os meios que tem ao seu dispor e que, no ato de projetar, reinventa. Além de fazer uso dos meios de seu próprio organismo em conjunção com os meios naturais presentes no ambiente, são acrescentados meios artificiais o que expande a capacidade humana de transformar a biosfera, ao mesmo tempo em que o humano transforma a si mesmo. Transformando a natureza, o ser humano transforma a sua própria natureza, eis o ensinamento de Marx.

Como animal simbólico e consequentemente social, pelo trabalho o ser humano produz a sua própria existência, ou seja, produz os meios de sua subsistência material e simbólica. Nesse seu aspecto ontológico, potencialmente o trabalho seria, portanto, projeto e processo por meio do qual se daria a "objetivação" do sujeito, quer dizer, a objetivação da subjetividade. Infelizmente, os modos de produção material e as relações sociais neles implicadas, que até agora a história nos legou, foram cada vez mais estreitando a margem libertária do trabalho até seu encolhimento alienante no modo de produção capitalista. Não obstante a relevância desse tema, não é por ele que caminharemos, pois isso nos afastaria do propósito que norteia este artigo e que está mais voltado para a explicitação das etapas, passos, graus que vão do design como projeto até alcançar sua etapa de integração e naturalização total na vida social.

A visão do trabalho concreto de Marx, de certa forma, ecoa na concepção que Mensvoort nos apresenta desse primeiro nível da criação que, antes de sua fase de produção e aceitação social, nasce na mente humana. Deve haver uma ideia, um sonho ou visão de como as capacidades humanas existentes podem ser expandidas. Esse nível sonhado ou imaginado constitui-se na incubadora de toda inovação cujo nascimento se dá na província dos poetas, artistas, escritores de ficção científica, designers e outros visionários.

Pensemos, por exemplo, na história do nascimento do hipertexto, na sua forma contemporânea em suporte computacional, de como ele foi imaginado e antecipado por visionários como Paul Otlet, Vannevar Bush, Douglas Engelbart e Ted Nelson que, em analogia com o funcionamento da memória associativa, tiveram a ideia de um arquitexto que permitisse o acesso à informação através de vínculos associativos, ligando um determinado assunto a outro em uma composição reticular (SANTAELLA, 2007, p. 299-328). Implantado como a linguagem própria das redes, depois da invenção da interface gráfica de usuário, o hipertexto passou a conectar, além dos textos, diferentes linguagens visuais e sonoras, até se transformar em hipermídia. É essa composição híbrida de linguagens que, hoje, crianças de menos de seis anos já dominam com 
presteza nos tablets e nos celulares. Mas, com isso, já estou me adiantando em relação aos níveis que se seguem ao nível da imaginação e do design como projeto.
OPE Este nível corresponde ao teste de viabilidade do proRACIO NALI ZAÇÃO jeto, quando a imaginação deve ser posta à prova. É o momento de criação de desenhos, de uma maquete, de um protótipo ou similares. Se nos voltarmos para a raiz latina "designare" (design), dentro dela encontra-se a palavra "signare" (signo). Antecedida do prefixo "de" (para fora), pode-se concluir que o design, nessa etapa de operacionalização, implica a noção de linguagem na sua realidade semiótica vasta que inclui, mas vai além da linguagem verbal, como meio imprescindível para externalizar a ideia mentalmente projetada. Portanto, esse primeiro degrau, para o qual o projeto avança, corresponde justamente ao sentido de operacionalidade, de experimentação sígnica do design, adequação da linguagem aos materiais e meios em que ela se corporifica.

No campo das novidades tecnológicas, não são raros os exemplos de prototipagem de designs que já estão operacionalizados, mas sem possibilidade de serem colocados no mercado devido à exorbitância do pre- 
ço. Nesse caso, o design tem de encontrar a chance de ser operacionalizado com materiais mais baratos ou esperar pelo aparecimento de materiais e meios ainda não existentes que o tornem viável.

Mensvoort apresenta uma série de exemplos para esse estágio de operacionalização, como a carne in vitro que traria uma solução sustentável e alternativa para as cruéis condições de criação e matança de animais, bastante discutidas nos livros de Harari (2015; 2016). Trata-se de um projeto que está sendo testado em laboratório, mas sua viabilização atingiria hoje preços exorbitantes (POST, 2011). Outros exemplos são o computador quântico que, aliás, já está operacionalizado, mas ainda em teste no mercado, a eletricidade sem fio, os micróbios engenheirados que poderiam transformar lixo de plantas em petróleo. Tragicamente, não é apenas a viabilidade que regula a passagem do nível de operacionalização para a sua aplicação no mercado, mas sim, a probabilidade de os investidores fazerem dinheiro com isso.

APL O que se tem aí é a passagem do laboratório para a torna reconhecível em um produto, nos móveis, nos CA carros, na vestimenta, em capas de livros e de CDs, C̃O em páginas da Web, em rótulos de produtos, em filmes publicitários, nos games e em uma infinidade de outras aparições. Dada a sua materialidade, costuma-se considerar que o design se reduz a esse nível. Contudo, ele pressupõe os dois níveis anteriores e repercute naqueles que vêm depois dele. O exemplo apresentado por Mensvoort é o google glass, de resto, um exemplo que acaba datando o seu texto, pois, de 2014, quando o texto foi escrito, para cá, a aplicabilidade desse design fracassou. Ficou muito longe da aceitabilidade dos designs cada vez mais leves e ergonômicos dos celulares e dos tablets

A aplicação, na verdade, depende muito da aceitabilidade, sem a qual um design se perde na poeira do tempo. Além disso, há muitos casos em que a aplicação fica por algum tempo restrita, um pouco à margem, passando quase despercebida. É o que aconteceu com as células solares, antes pouco empregadas 
e hoje visíveis nos tetos de uma grande percentagem de habitações na Alemanha, paradoxalmente um país em que o sol é visto como um presente dos céus. $\mathrm{O}$ carro elétrico também teve de ficar à espera de baterias mais poderosas para que pudesse ser viabilizado. Há casos ainda em que uma invenção desaparece por ser substituída por um projeto que a suplanta. Quem ainda se lembra do fax?

ACEI
TA
ÇÃO

Dos carros ao telefone, dos aviões ao computador, do e-mail ao WhatsApp, do GPS ao Wase, quem vive sem eles? São projetos cuja reprodução, padronização e familiaridade penetram pelas vias capilares da vida social. A aceitação depende da maneira como os usuários recebem esses novos produtos e, certamente, o design é fator crucial para essa aceitação ou não. É por acaso que se fala tanto em userfriendly quando se trata do design das interfaces nas plataformas computacionais?

São muitas as variáveis implicadas na aceitabilidade. Esta envolve, antes de tudo, a transição daquilo que à primeira vista é tido como artificial o que dificulta sua integração à normalidade e familiaridade do cotidiano. Para isso, o produto precisa se inserir, sem rupturas, nos hábitos existentes e o design tem de falar obrigatoriamente à intuição. Basta pensar na maneira como a televisão apareceu como um surplus ao uso doméstico do rádio, como os telefones celulares expandiram as funções dos telefones fixos, adaptando-se às agitações e turbulências da vida contemporânea, como o micro-ondas apressou e facilitou o des- 
congelamento e o cozimento dos alimentos, enfim, os exemplos são inumeráveis.

Várias vezes, para garantir a sua inserção na vida dos usuários, o design mimetiza a aparência e o modo de usar de um design anterior. Esse é o caso de muitas revistas eletrônicas que trazem o recurso de virar páginas imitando a ação que é própria da leitura de uma revista em papel. Enfim, tudo depende dos modos de absorção que a cultura define e que, quando atingem o ponto de penetração nas nervuras da vida, o design salta para ou se aprofunda no nível vital.
VITA Se o produto ganha aceitabilidade social, ele se torna vital. É incorporado organicamente na existência de cada ser humano no corpo da vida social. Quem ainda é capaz de viver sem um celular, depois de ter passado alguns dias com ele? Isso faz lembrar a frase bombasticamente pronunciada por Bruce Sterling no Transmediale-2015: "There is no scape" (Não tem escapatória). Telefone celular é o sonho irresistível das crianças, especialmente se alimentado por plataformas de games. É também a maneira mais natural dos idosos vencerem o sentimento de solidão. Tudo isso fica ainda mais inevitável, inexorável mesmo, quando se consideram todos os aplicativos com seus designs convidativos que transformam o celular em um faz tudo, um minúsculo conector supremo no espaço do planeta.

A intensidade com que esse pequeno aparelho se incorporou organicamente à existência individual e social pode ser verificada quando se passa pela experiência da perda: é como se o mundo desabasse. Diante disso, parece equivocada e simplória a avaliação, que se costuma fazer, de que se trata aí de dependência. A organicidade de sua penetração na vida torna-se tão naturalizada que equivaleria a dizer que somos de- 
pendentes de nossa mão direita ou do pé esquerdo.

É justamente a medida da falta que marca a passagem do degrau da aceitação para o degrau da vitalidade. Quando a falta implica uma ruptura nos hábitos e estilo de vida, isso significa que o produto se tornou vital, tendo se tornado perto do impossível viver sem ele, dada a enorme energia gasta no esforço desagradável para produzir as mudanças de hábitos que sua ausência traria. Outro equívoco é considerar que se trata apenas de um fenômeno psíquico. Certamente inclui o psíquico, mas suas consequências são pragmáticas, pois interferem em quase todos os filamentos das ações que comandam a nossa existência.

Certamente não há como negar que a obsolescência programada dos produtos e seus designs resulta da desmesura consumista do capitalismo. Contudo, não se pode deixar de considerar que existe um investimento em designs cada vez mais ergonômicos, cada vez mais integrados à sensorialidade e à sensibilidade do corpo humano. O que seria do celular sem o touchscreen e sua adaptabilidade aos dedos polegar e indicador? Prova disso pode ser observada na destreza, presteza e ligeireza com que jovens manipulam seus celulares na concha de suas mãos, o que remete àquilo que tão acertadamente Gibson (1986) concebeu como affordance, ou seja, a naturalidade com que as formas se oferecem a uma integração com o corpo humano. É essa notável aproximação e intimidade crescente que os designs atuais apresentam com o corpo humano e seus ambientes que nos leva ao sexto degrau da pirâmide.

INV Quanto mais vital, mais invisível um produto tende a se tornar. Mesmo que esteja ali, diante dos nossos SIB| olhos, seu uso e incorporação reflexa nos hábitos corriqueiros automatiza a visibilidade de sua presença. LIDA Entronizou-se de tal maneira no tecido da existência a DE ponto de não mais se distinguir da própria existência. Não é casual que as tecnologias atuais caminham irreversivelmente para a invisibilidade completa. Estão lá, têm agenciamento, interferem nos ambientes, mas não são visíveis. Esse é o caso da internet das coisas, com seus designs planejados para passarem despercebidos de modo a tornar ainda mais eficazes os seus efeitos.

Em 1991, Mark Weiser declarou que "as mais profundas tecnologias são aquelas que desaparecem. Elas se entrelaçam a tal ponto no tecido da vida cotidiana que se tornam indistinguíveis dela". Com isso, ele preconizava o destino cada vez mais invisível do computador. Hoje se fala em computação ubíqua e pervasiva, confirmando seu prognóstico. Em 2005, o relatório da internet da União de Telecomunicação Internacional $^{1}$, ao anunciar a internet das coisas, já dava razão a Weiser. Esta se define como a extensão da internet 1 Ver http://www.itu.int/osg/spu/publications/internetofthings/ 
no mundo físico, tornando possível a interação com objetos e a comunicação autônoma entre objetos o que se tornou possível porque a tecnologia faz uso das etiquetas de RFID (etiquetas de rádio frequência) e de redes de sensores sem fios. Prevê-se que seu desenvolvimento irá implicar também a incorporação de nanotecnologia. As RFID são fundamentais porque não há como ligar aparelhos e objetos cotidianos a grandes bases de dados e às redes, sem um potente sistema de identificação para reunir e registrar os dados sobre cada uma das coisas. E, para detectar mudanças na qualidade física das coisas, as tecnologias de sensores entram em ação, recurso importante para registrar mudanças no meio ambiente. Sensores em peças de vestuário inteligentes também irão detectar variações de temperatura no exterior e ajustar-se de acordo com elas, o que será um conforto para lugares cuja temperatura pode variar mais de dez graus na passagem da manhã para a tarde. Tudo isso significa que aquilo que costumávamos chamar de objetos estão se tornando sencientes, dotados de sensorialidade e de um certo grau de inteligência (ver SANTAELLA, 2013, p. 27-33).

Diante disso não é casual que o grande tema dos debates atuais esteja voltado para aquilo que está sendo chamado de "virada do não-humano", justamente o tópico central escolhido pelo Transmediale-2017. As pesquisas sobre cognição animal e a inteligência embutida nas coisas e nos ambientes descentrou a posição do humano cuja inteligência, sensorialidade e sensibilidade aparecem agora como uma forma hipercomplexa, mas compartilhada de cognição.
NATU No ápice da pirâmide encontra-se a naturalização. RALI ZAÇÃO Os inventos e seus produtos integram-se na vida com tal profundidade que parecem desde sempre ter sido parte inseparável dela, numa espécie de simbiose. É raro haver uma estabilização nesse topo da pirâmide por muito tempo. Provavelmente isso ocorre porque os produtos são continuamente substituídos por outros cujos designs são melhor desenvolvidos, seus materiais, formas e funções mais aperfeiçoados, mais estéticos, mais adequados e facilitadores do uso. Essas substituições, que se tornaram comuns a partir da revolução industrial, foram atingindo níveis de exacerbação crescentes dando origem às marcas e suas estratégias, o que transformou o design em uma questão obrigatória para todas as facetas das marcas, do seu gerenciamento, do seu marketing e de suas campanhas publicitárias, no universo altamente competitivo do capitalismo digital, globalizado.

Mensvoort dá o cozimento dos alimentos como exemplo de um invento que até hoje permanece inabalável no topo da pirâmide. Aliás, é a diferença entre o $\mathrm{Cru}$ e o cozido que Lévy-Strauss escolheu para evidenciar 
a linha divisória entre natureza e cultura. O Cru e o cozido é o primeiro de quatro volumes sob o título geral de As mitológicas, nos quais Lévy-Strauss desenvolveu um estudo aprofundado dos mitos indígenas. O Cru e o cozido dá início à volumosa obra porque o fogo e o cozimento dele decorrente são tomados como a ponte de ligação entre a natureza e a cultura humana. O cru, de um lado, estaria com a natureza e o cozido, de outro, instauraria a cultura.

Que haja para o ser humano uma linha divisória entre natureza e cultura é uma questão hoje bastante debatida. Não obstante os debates que colocam esse binômio sob interrogação, é muito comum a consideração do design tecnológico como uma segunda natureza quando ele se integra de modo inconsútil na vida humana. É dessa metáfora que Mensvoort faz uso quando diz que a naturalização de um invento se dá quando uma segunda natureza se converte em primeira natureza. Tenho argumentado com certa veemência (SANTAELLA, 2015a) contra a polarização entre natureza e cultura, um binômio que não faz mais nenhum sentido nesta era do Antropoceno (SANTAELLA, 2015b), se é que, em algum momento, essa distinção fez sentido no que diz respeito ao humano.

De resto, não só ao humano quando se sabe que os outros animais, desde aqueles dotados de cérebros minúsculos até aqueles dotados de cérebros mais avantajados sobrevivem a partir de programas genéticos devidamente codificados, quando se sabe que até mesmo as plantas estabelecem intercursos comunica- cionais graças a formas de sentir e pensar muito específicas. Tudo isso nos leva a considerar que, quando Flusser declara que o mundo é codificado, as pesquisas recentes estão comprovando que não se trata de uma simples metáfora.

Sem entrarmos nas controvérsias sobre o momento em que se deu a emergência do humano, desde que se ergueu sobre as duas pernas, na posição ereta que liberou a testa para o crescimento do neocortex e as mãos para a ação inteligente, juntamente com o encolhimento da mandíbula, a natureza para o humano, é, de saída, natureza culturalizada. Desde que lascou a pedra, dissipou-se para sempre a ideia de uma primeira e uma segunda natureza ou qualquer outro número de naturezas. O projeto (design) humano evoluiu na medida mesma da evolução de seus projetos (designs). O design do humano é um projeto em sua própria essência inacabado, em processo. Só isso pode nos levar a compreender porque somos o único animal que desaba de rir e sucumbe na dor, a compreender porque nosso desígnio é incessantemente projetar, conceber, sem que com isso seja possível desvendar nosso mistério, paradoxos, misérias, conquistas, fracassos e esperanças. Em suma, tudo parece indicar que Verbeek está coberto de razão quando afirma que "to be human is to design". 
REFERÊNCIAS FLUSSER, Vilém. O mundo codificado: por uma filosofia do design e da comunicação, Rafael Cardoso (org.); Raquel Abi-Sâmara (trad.). São Paulo: CosacNaify, 2007.

GIBSON, James J. The ecological approach to visual perception. Hillsdale, New Jersey: Lawrence Erlbaum Associates, Publishers, 1986.

HARARI, YuvalNoah. Sapiens. Uma breve história da humanidade,Janaina Marcoantonio (trad.). Porto Alegre: L\&PM Editores, 2015.

. Homo Deus. Uma breve história do amanhã, Paulo Geiger (trad.). São Paulo: Companhia das Letras, 2016.

LÉVI-STRAUSS, Claude. O cru e o cozido. Mitológicas 1. São Paulo:CosacNaify, 2004.

MARX, Karl.Grundrisse: Manuscritos Econômicos de 1857-1858. Esboços da Crítica da Economia Política. São Paulo: Boitempo Editorial, 2011.

MASLOW, A.H. A theory of human motivation. Psychological Review 50(4), 1943, p. 370-396. 
MENSVOORT, K. van. Pyramid of Technology: How Technology Becomes Nature in Seven Steps. Eindhoven University Lecture series. TechnischeUniversiteit Eindhoven, 2014.

POST, Mark. Meet the new meat. Lecture at Next Nature Power Show. In http://www.youtube.com/ watch?v=V2oB38a6RTg, 5 Novembro 2011, Stadsschouwburg Amsterdam. Acesso: 04/02/2017.

SANTAELLA, Lucia. Linguagens líquidas na era da mobilidade. São Paulo: Paulus, 2007.

Comunicação ubíqua.

Repercussões na cultura e educação. São Paulo: Paulus, 2013.

\section{Adeus às fronteiras entre}

natureza e cultura. Observatório Cultural-Itaú 19, 2015a, p. 17-23. In https://issuu.com/itaucultural/ docs/obs19_book_issuu_af. Acesso: 02/02/2017.

A grande aceleração e o campo comunicacional. Intexto, Porto Alegre, UFRGS, n. 34, 2015b, p. 46-59.

. Astúcias do design. Flusser

Studies 21,Junho 2016, p. 5-15

SHAVIRO, Steven. Discognition. London: Repeater Book, 2015.

SOUZA, Taiz. A Pirâmide de Maslow: A hierarquia das necessidades humanas. In http://www.psiconlinews.com/2015/11/piramide-de-maslow-hierarquia-das-necessidades-humanas.html, 2015. Acesso: 05/02/2017.
WEISER, Mark. The Computer for the 21stCentury. Scientific American, September. In https://pdfs. semanticscholar.org/oe2f/917aeb87dc4c51248ca938a5ee9eb17de64a.pdf, 1991. Acesso: 10/02/2010. 